\title{
Protección jurídica al inversionista en el mercado de valores colombiano
}

\section{Legal protection of the investor in the Colombian securities market}

https://doi.org/10.15332/iust.v0i15.2091

Camilo E. Quiñónez Avendaño

Docente asociado Universidad Autónoma de Bucaramanga, abogado, especialista en Derecho Comercial, especialista en Derecho Empresarial; magister en Derecho Económico, candidato a doctor en Derecho Universidad Externado de Colombia.

Correo electrónico: equinone@unab.edu.co.

\section{Resumen}

La protección jurídica de los inversionistas en el mercado de valores colombiano está integrada por institutos, organismos y procedimientos que forman parte de las normas sectoriales de dicho mercado, de la protección al consumidor financiero, del derecho mercantil y del derecho penal. El objetivo de este artículo es analizar el sistema de protección al inversionista para mostrar que el principal instrumento utilizado por el Estado colombiano es la regulación de información.

Palabras clave: Inversionistas, mercado de valores, consumidor financiero, derecho del mercado de valores.

\begin{abstract}
The legal protection of investors in the Colombian stock market is made up of institutes, agencies and procedures that form part of the sectoral rules of that market, of protection for the financial consumer, of commercial law and of criminal law. The objective of this article is to analyze the system of protection to the investor to show that the main instrument used by the Colombian State is the regulation of information.
\end{abstract}

Keywords: Investors, securities market, financial consumer, legal protection.

\section{Résumé}

La protection juridique des investisseurs sur le marché boursier colombien est constituée d'instituts, d'agences et de procédures faisant partie des règles sectorielles de ce marché, de la protection des consommateurs financiers, du droit commercial et du droit pénal. L'objectif de cet article est d'analyser le système de protection des investisseurs pour montrer que le principal instrument utilisé par l'État colombien est la réglementation de l'information.

Mots-clés: Investisseurs, marché boursier, consommateur financier, droit boursier. 



\section{Protección jurídica al inversionista en el mercado de valores colombiano}

Camilo E. Quiñónez Avendaño

\section{INTRODUCCIÓN}

Se describe y analiza la protección que el derecho colombiano ofrece a los inversionistas en valores: en normas sectoriales del mercado; en el derecho mercantil; en la normativa del consumidor financiero y en normas de derecho penal. En cada una de estas áreas se identifica los mecanismos o procedimientos utilizados por el Estado, el sujeto protegido y el fundamento de la protección.

El contenido que se presenta forma parte de una investigación jurídica, exploratoria que hace uso de la descripción y el análisis para ofrecer una visión integrada de la tendencia del derecho colombiano a incentivar la inversión, usando como instrumento la regulación económica. El problema de investigación objeto de estudio fue ¿Cuál es el alcance de la protección jurídica del inversionista en el mercado de valores en Colombia?, para lo cual se fijó como objetivo general: formular una visión integrada de la protección jurídica a los inversionistas en el mercado de valores colombiano. En el presente texto se muestra una síntesis del desarrollo de uno de los objetivos específicos de la investigación, referido a explicar las distintas manifestaciones de la protección jurídica del inversionista en Colombia.

\section{CONSIDERACIONES PREVIAS}

La intervención del Estado en la economía, fundamento de esta investigación, plantea que aun cuando los mercados son el centro de la economía, no pueden dejarse funcionar solos, no siempre funcionan como debieran porque no son ninguna panacea, y porque el Gobierno siempre es un aliado relevante para ellos (Stiglitz, 2003).

La regulación económica del mercado de valores concreta la labor de intervención, en un escenario al que acuden emisores de valores a obtener financiación de los inversionistas, mediante la venta que los primeros hacen a los segundos de papeles negociables denominados valores. El fin último de la regulación económica es 
garantizar que los agentes del mercado puedan mantenerse en él, en condiciones de equidad, transparencia y estabilidad (López \& David, 2004).

Desde el 2005, el Estado colombiano ha utilizado la regulación como instrumento para incentivar o inducir a inversionistas, ya provenientes de la inversión extranjera directa $^{1} \mathrm{o}$ inversionistas a través del mercado de valores ${ }^{2}$, a disponer de sus excedentes monetarios para insertarlos en el circuito macroeconómico colombiano.

\section{REFERENTES INTERNACIONALES DE LA PROTECCIÓN JURÍDICA DEL INVERSIONISTA EN VALORES EN COLOMBIA}

La protección jurídica de los inversionistas en el mercado de valores surge como una recomendación de la Organización Internacional de Comisiones de Valores $(\mathrm{OICV})^{3}$, quien propone a los reguladores proteger a los inversionistas de la mala conducta de los intermediarios, de las prácticas engañosas, de la manipulación del mercado y del uso de información privilegiada.

La recomendación internacional está incorporada a la regulación en España, Brasil, Chile, México, Perú y Colombia. Cada país la ha expresado y desarrollado de distinta forma: En España (Ley 47 de 2007 modificada por Ley 24 de 1988, como protección al inversor; en Brasil (Ley 6385 de 1976 y Ley 10303 de 2001), protección de los titulares de valores mobiliarios; en Chile (Ley 18045 de 1981), resguardar los derechos de los inversionistas; en México (Ley del Mercado de Valores), proteger los intereses del público inversionista; en Perú (Decreto Supremo 93 de 2002) la adecuada protección a los inversionistas y en Colombia (Ley marco del Mercado de Valores: 964 de 2005), como la protección a los derechos de los inversionistas.

La recomendación de ese organismo internacional ha contribuido a que los reguladores económicos fijen en su normativa interna esos estándares o principios y una regulación basada en la revelación de información. Un estudio realizado por el Banco Mundial mostró que en los mercados emergentes se han construido estándares e instituciones reguladoras, los países en desarrollo adoptaron un marco fundamentalmente basado en la revelación de información, disciplina autoimpuesta del mercado y de la industria (Carmichael \& Pomerleano, 2005, p. 135).

Frente a los países que no incorporan al derecho interno el estándar de proteger al inversionista en valores, la recomendación de la OICV, por tratarse de un organismo privado y técnico, opera como derecho blando o soft law, esto es, no tienen un carácter

1 Mediante Ley 963 de 2005 se expidió la ley de estabilidad jurídica para los inversionistas. Esta disposición fue derogada mediante Ley 1607 de 2012.

2 Ley 964 de 2005 ley marco del mercado de valores colombiano.

3 La OICV (IOSCO - International Organization of Securities Commissions) existe y funciona como un foro de cooperación internacional entre reguladores de los mercados de valores. Agrupa autoridades de supervisión y regulación de los mercados financieros a escala mundial, y su objetivo último es la armonización de las normas y de los procedimientos por los que se rigen dichos mercados. 
obligatorio, vinculante y en ellas está ausente su imperatividad y coercibilidad. Estas soluciones blandas son un rasgo distintivo de la globalización del derecho que se ofrecen precisamente para los problemas más duros que suscita, siempre han existido en todas las ramas del Derecho como declaraciones exhortatorias y grandes principios (Laporta, 2007).

La protección jurídica a los inversionistas en valores, además de referentes normativos de derecho blando, cuenta con referentes doctrinales que permiten: i) justificar la regulación de información; y ii) definir cómo se protege al inversionista en valores.

El primero de los hallazgos muestra que al inversionista se le protege para evaluar los riesgos y beneficios asociados con su inversión, lo que reclama diseñar instrumentos necesarios para que cuenten en forma oportuna, completa y fidedigna; clara y económica, con la información relevante relativa a la emisión, colocación e intermediación de valores (Rivero, 2003).

Respecto a la segunda línea del desarrollo doctrinal, se encuentra que una vez los Estados deciden proteger al inversionista en valores, se hace necesario preguntarse ¿cómo se protege? La respuesta dada a este interrogante mostró que al inversionista se le protege con regulación de información que hace posible la transparencia informativa (Pérez, 2005); se le protege con educación financiera dado que la transparencia, como mecanismo de protección, presenta un obstáculo relacionado con la calidad técnica de la información que se lanza al mercado que impide al inversionista entenderla y asimilarla (Belando, 2004), y se le protege como consumidor financiero mediante la regulación de información (Corredor, 2015) que debe tener en cuenta, entre otros aspectos, el acceso a la información a todo el público sin restricciones, la existencia de legales para mitigar conflictos de intereses y el reconocimiento de unos deberes mínimos de conducta por parte de los intermediarios de valores en materia de lealtad, secreto, confidencialidad y asesoría.

Los referentes legales y doctrinales se tomaron como referencia en la investigación, para clasificar en los próximos apartados la manera como se concreta en Colombia la protección, y así presentar los resultados.

\section{PROTECCIÓN JURÍDICA DEL INVERSIONISTA EN EL DERECHO DEL MERCADO DE VALORES - DMV}

La protección a los derechos de los inversionistas es el enunciado general trazado por el derecho colombiano en la Ley marco del Mercado de Valores como objetivo de la intervención estatal, que ha dado sustento a disposiciones legales que integran 
una manifestación del derecho que denominamos Derecho del Mercado de Valores $\mathrm{DMV}^{4}$ o normas sectoriales del mercado de valores ${ }^{5}$.

En desarrollo de dicho objetivo, se impone a emisores e intermediarios de valores deberes de información orientados a proteger al mercado, a garantizar que en él exista información clara, completa, veraz, comparable y oportuna a punto que se genere una confianza del inversionista. El cumplimiento de estos deberes se verifica con los siguientes instrumentos:

a. Facultad de autorización de la Superintendencia Financiera de Colombia. Corresponde a este organismo autorizar el ingreso de nuevos emisores, de oferta pública de valores; así como el ingreso y permanencia en el mercado de intermediarios de valores; y ejercitar las acciones necesarias para controlar el riesgo operativo de los emisores de valores.

b. Sistema Integral de Información del Mercado de Valores - SIMEV. Mediante la existencia de esta base de datos se garantiza al inversionista que pueda conocer información mediante el acceso a tres registros: Registro Nacional de Valores y Emisores - RNVE; Registro Nacional de Profesionales del Mercado de Valores - RNPMV y Registro Nacional de Agentes del Mercado de Valores - RNAMV. El inversionista podrá verificar si negocia o no con operadores autorizados, sin que ello signifique un compromiso estatal sobre la solvencia del emisor o una garantía de que la rentabilidad esperada sea real.

c. La autorregulación de los mercados de valores. El derecho colombiano calificó la autorregulación como una actividad del mercado de valores que ejerce función disciplinaria, normativa y de supervisión sobre los intermediarios de valores. La finalidad que persigue esta figura es velar por que los intermediarios cumplan la normativa estatal, los reglamentos expedidos por el Autorregulador del Mercado de Valores - AMV y los reglamentos de los sistemas de negociación a través de los cuales se comercialicen los valores objeto de una oferta pública. Es de advertir, que el inversionista no tiene acceso directo al mercado y que solo acude a él a través de un intermediario destinatario de un deber de sometimiento a la normativa estatal y privada emitida por el AMV.

$4 \quad$ El DMV es un área de conocimiento del moderno derecho económico. Se ocupa de regular las relaciones que ocurren en el mercado de valores, sobre documentos denominados "valores", sea que se negocien en oferta pública o en oferta privada, dentro o fuera de una bolsa de valores, y en especial, regular las actividades que se realizan en el mercado de valores. Estas actividades son: la emisión y la oferta de valores; la intermediación de valores; la administración de fondos de valores, fondos de inversión, fondos mutuos de inversión, fondos comunes ordinarios, fondos comunes especiales; el depósito y la administración de valores, la administración de sistemas de negociación o de registro de valores, futuros, opciones y productos derivados; la compensación y liquidación de valores; la calificación de riesgos; la autorregulación; y el suministro de información al mercado de valores, incluyendo el acopio y procesamiento de la misma. Esta definición fue construida por el autor de esta investigación.

5 La expresión normas sectoriales se utiliza para referirnos a la Ley 964 de 2005, Decreto 2555 de 2010 y disposiciones expedidas por el Estado colombiano para ordenar el mercado de valores. 
d. Acción disciplinaria adelantada por el AMV. El AMV tiene la facultad o potestad atribuida por el derecho colombiano para imponer sanciones derivadas en el incumplimiento de las normas del mercado de valores y de los reglamentos de autorregulación y de los reglamentos de las bolsas de valores, de los sistemas de negociación y de los sistemas de registro, y si es del caso imponer las sanciones a que haya lugar. Dicha función se ejerce mediante el inicio de procesos disciplinarios, donde se investiga a intermediarios de valores, asociados autorregulados, autorregulados voluntariamente, inscritos en AMV y personas naturales vinculadas.

e. Acción de clase. Se trata de una acción de responsabilidad civil que puede instaurar ante los jueces de la república, un grupo de inversionistas a quienes se cause perjuicio patrimonial por el uso o suministro de información privilegiada en el mercado de valores para adquirir o aconsejar la adquisición o venta de un valor en el mercado (art. 45 Ley 45 de 1990).

f. Posibilidad de que los emisores contemplen en su normativa interna las normas de buen gobierno societario o buen gobierno corporativo para garantizar un trato igualitario a los socios considerados como minoritarios.

g. Prohibición de uso de información privilegiada. Por información privilegiada la normativa de mercado de valores en Colombia considera que es aquella información de carácter concreto que no ha sido dada a conocer del público y que de haberlo sido la habría tenido en cuenta un inversionista medianamente diligente y prudente al negociar los respectivos valores. La protección jurídica al inversionista se concreta en que se establece una prohibición general, una prohibición especial, y se fijan sanciones por infracción a estas prohibiciones (Quiñónez, 2011). El mandato general prevé que ninguna persona podrá, directamente o a través de interpuesta persona, realizar una o varias operaciones en el mercado de valores utilizando información privilegiada. El mandato especial va dirigido a quienes hayan recibido información privilegiada en ejercicio de sus funciones o los intermediarios de valores cuando realicen alguna de las siguientes conductas: 1) Suministren dicha información a un tercero que no tiene derecho a recibirla. 2) En razón a dicha información aconsejen la adquisición o venta de un valor en el mercado (art. 75 de la Ley 45 de 1990).

Los instrumentos reseñados provenientes del DMV o normas sectoriales del mercado de valores están orientados a organizar el mercado, a generar confianza en este y a prevenir riesgos en el sistema. En principio, por su diseño se percibe que no ofrecen protección directa al inversionista ni tampoco le reconocen derechos subjetivos. No obstante, consideramos que el inversionista recibe una protección indirecta de esta normativa en tanto que es un agente necesario en el mercado, un agente sin el cual no hay mercado.

La expresión mercado, significa un conjunto de compradores y vendedores que, por medio de sus interacciones reales o potenciales, determinan el precio de un 
producto o de un conjunto de productos (Pyndick, 2003). El lugar del comprador en el mercado de valores lo ocupa el inversionista y el de vendedor el emisor de valores. El primero, es un agente superavitario, persona natural o jurídica, que dispone de recursos monetarios y ha decidido orientarlos hacia la inversión en valores o activos financieros, en busca de dar uso productivo a sus recursos, de manera eficiente, con el fin de obtener rendimientos que incrementen su patrimonio; el segundo, esto es, el emisor de valores lo entendemos como, un sujeto de derechos, específicamente una persona jurídica -con ánimo de lucro o sin él, de naturaleza pública o privada-, que crea, emite y pone en circulación valores, títulos valores, activos financieros o valores en papel, materializados o desmaterializados, ya de contenido crediticio, reales o de tradición o corporativos o de participación.

La justificación de la protección al mercado obedece a razones de interés público. Algunos Estados han reconocido que si bien en los mercados de valores se negocia con recursos monetarios provenientes del sector privado, las relaciones que ocurran en él competen al Estado, dado su papel de director general de la economía. Por esta razón, califican en la Constitución Política o en su normativa interna, como de interés público las actividades financiera, aseguradora, bursátil y cualquier actividad relacionada con la captación, el manejo, y el aprovechamiento de recursos captados del público.

Con este enfoque se plantea la fórmula "interés público igual a control público", lo que supone un sometimiento de los particulares a una serie de deberes impuestos por el Estado. El calificativo de interés público encuentra fundamento en la teoría de la regulación basada en el interés público que utiliza este concepto como una pauta que permite juzgar la actividad política y jurídica (Fontecilla, 2006).

En Colombia la Constitución Política califica la actividad bursátil como de interés público (art. 334). Por su parte, la Corte Constitucional reitera que la actividad bursátil, por expresa disposición constitucional, es de interés público, lo que significa que el mercado bursátil se encuentra sometido al poder de policía administrativo, es decir, a la inspección, vigilancia y control del Estado a través de la Superintendencia de Valores, hoy Superintendencia Financiera de Colombia, la cual debe intervenir para mantener el mercado bursátil debidamente organizado, y velar porque quienes participan en él desarrollen su actividad en condiciones de igualdad, transparencia y no se ponga en peligro ni se lesione el interés público y específicamente el interés de los inversionistas ${ }^{6}$.

El papel del Estado en el mercado de valores se concreta en impedir que los operadores desarrollen su actividad guiados por la ley del mercado. Existe un orden jurídico del mercado, conforme al cual el ejercicio de la actividad bursátil es reglado, como quiera que la legislación y la labor gubernamental de inspección señalan cuáles transacciones deben llevarse a cabo obligatoriamente a través de

6 Corte Constitucional Colombiana, Sentencias SU- 166 de 1999 M.P. Alejandro Martínez Caballero, y C-860 de 2006 M. P. Humberto Sierra Porto. 
bolsas de valores, qué montos y cómo deberá efectuarse cada transacción Se trata igualmente de una actividad sometida a autorización gubernamental previa, intervenida por el Estado de forma especial para prevenir conductas delictivas, tales como el lavado de activos y la utilización de esta labor para fines diferentes al interés público de lo cual se deduce también que en el mercado bursátil está presente la potestad administrativa sancionadora del Estado?.

La intervención no está orientada a restaurar o promover la competencia en el mercado, sino a proteger el interés que le asiste al Estado en generar confianza del inversionista en el mercado y así proteger la inversión. Al existir inversionistas confiados y dispuestos a invertir, hay emisores de valores con recursos monetarios que invierten en su proceso productivo, lo que genera empleo e ingresos de otro segmento de la población. Estos ingresos a su vez son invertidos en el mercado en consumo, ahorro o inversión. En síntesis, la confianza que los inversionistas tengan en el mercado que los lleva a invertir y contribuye a mejorar los indicadores macroeconómicos en un mercado.

\section{PROTECCIÓN DEL INVERSIONISTA EN DERECHO MERCANTIL}

La protección del inversionista se complementa con algunos instrumentos o mecanismos provenientes del derecho mercantil, área que si bien no ha sido construida para promover los mercados de valores, regula la relación entre el inversionista que tenga la calidad de accionista y la sociedad emisora de las acciones. Los rasgos distintivos de la protección son:

a. Se reconoce expresamente derechos del inversionista que tenga la calidad de accionista: Derecho a participar en la distribución de dividendos; derecho a participar en la distribución del remanente de la liquidación del patrimonio social; derecho a asistir con voz y voto a las reuniones de la Asamblea General de Accionistas; el derecho de retiro; el derecho a ser representado en las reuniones de Asamblea General de accionistas; el derecho a suscribir acuerdos de accionistas y el derecho a ejercer la inspección individual sobre libros y papeles de la sociedad (arts. 373 a 460 Código de Comercio colombiano).

b. Implementación de estándares para el suministro de la información financiera (Ley 1314 de 2009). A partir del 2009 se fijan principios y normas de contabilidad e información financiera y de aseguramiento de la información acordes con estándares internacionales de aceptación mundial, aptos para brindar información financiera comprensible, transparente y comparable, pertinente y confiable útil para el Estado, los inversionistas actuales o potenciales, los propietarios, funcionarios y empleados de las organizaciones empresariales. Con este instrumento de protección, el sistema de información

$7 \quad$ Sentencia C- 406 de 2004. M.P. Clara Inés Vargas Hernández. 
contable, una de las fuentes de información para el inversionista, ofrecerá información clara, veraz, suficiente, comparable guiada por estándares internacionales.

En el Derecho mercantil se protege solamente a quien tenga la calidad de accionista. La protección comercial deja a un lado al consumidor para ocuparse de proteger a quien ha cumplido con la obligación de hacer el aporte, en la época, forma y lugar convenidos; igualmente deja por fuera a los tenedores de valores que no sean acciones. Esta protección se ofrece en dos planos, uno patrimonial y otro extrapatrimonial. El primero de ellos referido al retorno de la inversión, y el segundo a derechos administrativos radicados en cabeza de quien ha sido socio.

\section{PROTECCIÓN DEL INVERSIONISTA DESDE LA NORMATIVA DEL CONSUMIDOR FINANCIERO}

En la normativa de protección al consumidor financiero, se registra en Colombia un desarrollo del derecho del consumo o derecho del consumidor a un ámbito muy particular como es el sector financiero colombiano. A partir de la expedición de la Ley 1328 de 2009 se introduce en el Derecho colombiano una categoría conceptual denominada consumidor financiero. Este concepto jurídico se aplica al inversionista $y$ al potencial inversionista, tanto en el mercado bancario como en el mercado de valores. Calificar al inversionista como consumidor financiero se hace para crear o insertar en el orden jurídico instrumentos o mecanismos de protección que se concretan en:

a. Reconocimiento expreso de derechos. Se reconoce que el inversionista consumidor financiero tiene los siguientes derechos: Derecho de recibir de parte de las entidades vigiladas productos y servicios con estándares de seguridad y calidad, de acuerdo con las condiciones ofrecidas y las obligaciones asumidas por las entidades vigiladas; derecho a tener a su disposición, en los términos establecidos en la presente ley y en las demás disposiciones de carácter especial, publicidad e información transparente, clara, veraz, oportuna y verificable, sobre las características propias de los productos o servicios ofrecidos y suministrados; derecho a exigir la debida diligencia en la prestación del servicio por parte de las entidades vigiladas; derecho a recibir una adecuada educación respecto de las diferentes formas de instrumentar los productos y servicios ofrecidos, sus derechos y obligaciones, así como los costos que se generan sobre estos, los mercados y tipo de actividad que desarrollan las entidades vigiladas así como sobre los diversos mecanismos de protección establecidos para la defensa de sus derechos, derecho a presentar de manera respetuosa consultas, peticiones, solicitudes, quejas o reclamos ante la entidad vigilada, el Defensor del Consumidor Financiero, la Superintendencia Financiera de Colombia y los organismos de autorregulación y los demás derechos que se establezcan en 
esta ley o en otras disposiciones, y los contemplados en las instrucciones que imparta la Superintendencia Financiera de Colombia.

b. Se crean mecanismos para la protección de los derechos del consumidor financiero: posibilidad de formular quejas ante el autorregulador del mercado de valores y ante el defensor del consumidor financiero, orientadas a imponer sanciones al intermediario. Estos mecanismos no se han diseñado para que el inversionista perjudicado obtenga indemnización de perjuicios que se causen por las actuaciones de los intermediarios.

c. Se impone a los inversionistas el deber de recibir educación sobre inversiones, de manera que pueda conocer los riesgos relacionados con las inversiones, al conocimiento de la protección estatal, y en especial a la administración de riesgos.

d. Se crea el centro de conciliación y arbitraje del AMV como un mecanismo alterno para solución de conflictos patrimoniales mediante un trámite sencillo y efectivo.

e. Se impone a los intermediarios deberes en su relación con el inversionista: diligencia; dar al inversionista una libertad de elección respecto al intermediario que les asesore en sus decisiones de inversión; manejar adecuadamente los conflictos de interés; e informar sobre los costos asociados con la inversión.

Los mecanismos y procedimientos aquí mencionados han sido creados como instrumentos para proteger a toda persona que sea consumidor financiero en el sistema financiero, asegurador y del mercado de valores. La normativa protectora (Ley 1328 de 2009) reconoce como consumidor financiero a todo cliente, usuario o cliente potencial de las entidades vigiladas por la Superintendencia Financiera, y fija el significado de cada una de estas categorías, así: Cliente: Es la persona natural o jurídica con quien las entidades vigiladas establecen relaciones de origen legal o contractual, para el suministro de productos o servicios, en desarrollo de su objeto social. Usuario: Es la persona natural o jurídica quien, sin ser cliente, utiliza los servicios de una entidad vigilada. Cliente potencial: Es la persona natural o jurídica que se encuentra en la fase previa de tratativas preliminares con la entidad vigilada, respecto de los productos o servicios ofrecidos por esta.

La razón de conceder al inversionista el estatus de consumidor financiero puede explicarse desde dos perspectivas teóricas, de una parte, considerar que es un sujeto débil y desinformado (Valenzuela, 1993), y de otra, que es un sujeto que opera en mercados donde hay asimetría de información (Ruiz, 2002).

La Corte Constitucional colombiana utiliza los dos referentes teóricos mencionados, parte de expresar que las entidades bancarias tienen una posición dominante frente a los usuarios del sistema financiero, circunstancia que impone al Estado el deber de controlar su actividad y evitar cualquier posibilidad de abuso ${ }^{8}$.

8 Corte Constitucional colombiana. Sentencia T177 de 2013. M. P. Nilson Pinilla Pinilla. 
En igual sentido, ha hecho explícita la protección al consumidor financiero, bajo el argumento que las condiciones del mercado y la disparidad entre los agentes del mismo, han impuesto el deber de intervenir para proteger derechos de sujetos en condición de debilidad o vulnerabilidad frente a otros cuya situación los convierte en dominantes .

El desarrollo jurisprudencial de la protección al consumidor financiero se complementa con la justificación de la intervención estatal en la economía por razones de orden macroeconómico. Al Estado le interesa controlar ciertos efectos macroeconómicos que la actividad financiera genera y el mantenimiento de la confianza en el público en las instituciones que conforman el sistema financiero ${ }^{10}$. Igualmente, la Corte Constitucional colombiana reconoce que el Estado tiene la obligación de intervenir en la economía para remediar las fallas del mercado y promover desarrollo con equidad ${ }^{11}$.

Las fallas a que hace referencia la Corte Constitucional colombiana en teoría económica se denomina asimetría de información. Esta asimetría se produce cuando el emisor dispone de información relevante que no haya sido objeto de publicidad, pero que sin embargo pueda ser conocida de forma privada por algunos inversionistas. Mientras la información no sea objeto de publicidad, se crea un problema de selección adversa, a tal punto que se impone un riesgo de información sobre los inversionistas. Las pérdidas de los desinformados van a ser igual a las ganancias de los informados, por lo que aquellos se protegerán del riesgo de información pidiendo mayores responsabilidades ex ante (García, 2002).

La selección adversa (Pyndick, 2003), es un tipo de falla del mercado provocado por la información asimétrica, se presenta cuando una de las partes involucradas en la operación tiene más información acerca del valor sobre el cual se está realizando la transacción, incide en la formación de precios y en la toma de decisiones del inversionista, quien va a estar más expuesto frente al incumplimiento del emisor. La selección adversa va a estar acompañada de riesgo moral, que se presenta cuando la persona cuya conducta no se observa puede influir en la probabilidad de recibir una indemnización o en su cuantía.

En este contexto de protección al inversionista una vez más el Estado colombiano toma como referente la información. Aquí la información pasa de ser un problema económico de formación de la demanda y toma de decisiones de consumo para convertirse en un instrumento jurídico de protección de los derechos de los consumidores y de acceso a canales de reclamos y resarcimiento (Blanco, 2012).

9 Corte Constitucional colombiana. Sentencia C-313 de 2013. M. P. Gabriel Eduardo Mendoza Martelo.

10 Corte Constitucional colombiana. Sentencia C-909 de 2012. M. P. Nilson Pinilla Pinilla.

11 Corte Constitucional colombiana. Sentencia C-197 de 2012. M.P. Jorge Pretelt Chaljub. 


\section{PROTECCIÓN DEL INVERSIONISTA EN VALORES Y DERECHO PENAL}

En el derecho penal colombiano la protección jurídica de los inversionistas se concreta con la existencia de dos tipos penales. De una parte, dentro de los delitos contra el patrimonio económico, como una defraudación, se ha tipificado la utilización indebida de información privilegiada ${ }^{12}$, y de otra, dentro de los delitos contra el sistema financiero, la manipulación fraudulenta de especies inscritas en el Registro Nacional de Valores e Intermediarios ${ }^{13}$.

\section{Utilización indebida de información privilegiada}

La redacción del tipo penal denominado utilización indebida de información privilegiada tiene una cobertura general, es decir, para situaciones ocurridas fuera del mercado de valores, y una especial, de la que se extrae la protección implícita al inversionista. Los dos campos normativos son: i. El que como empleado o directivo o miembro de una junta u órgano de administración de cualquier entidad privada, con el fin de obtener provecho para sí o para un tercero, haga uso indebido de información que haya conocido por razón o con ocasión de su cargo o función y que no sea objeto de conocimiento público, incurrirá en multa; y ii. el que utilice información conocida por razón de su profesión u oficio, para obtener para sí o para un tercero, provecho mediante la negociación de determinada acción, valor o instrumento registrado en el Registro Nacional de Valores ${ }^{14}$, siempre que dicha información no sea de conocimiento público.

El análisis del segundo contexto, que es el que guarda relación directa con esta investigación, se explica a partir del lenguaje técnico del contexto donde se protege al inversionista, esto es, el del mercado de valores: Los elementos para el análisis son:

- Sujeto activo de la conducta. La sanción se aplica a cualquier persona, no reclama una calidad específica, pero es preciso que, quien emplea la información haya tenido acceso a ella por razón de su profesión u oficio. En el lenguaje de mercado de valores a esta persona se le denomina insider $^{15}$ y en tal categoría se incluyen los administradores, directivos, miembros de cualquier nivel de la organización y las personas que debido a su actividad profesional (agentes y profesionales del mercado de valores) o empresarial prestan apoyo a la organización y en tal carácter tienen acceso a información reservada. El propósito de la norma es evitar que el insider divulgue o dé a conocer información.

12 Código Penal colombiano. Art. 258 modificado por la Ley 1474 de 2011.

13 Código Penal colombiano. Art. 317.

14 Con la expedición de la Ley 964 de 2005 el nombre es Registro Nacional de Valores y Emisores.

15 Esta expresión en castellano tiene el siguiente alcance: "persona enterada" o "empleado de la casa". 
- Conducta. La conducta que se sanciona es utilizar la información a la que ha tenido acceso por razón del cargo o la actividad empresarial o profesional que desarrolla. Esto significa que en la descripción normativa penal, no caben aquellas personas que conocen la información desde afuera de la organización conocidos como outsiders.

- El provecho al que se refiere la norma se presenta cuando se logra una ganancia o cuando se evita una pérdida mediante la negociación de un valor.

- Los valores a los que hace referencia la norma, son documentos representados en papeles que contienen derechos de naturaleza negociable, que hacen parte de una emisión y que tienen por objeto o efecto la captación de recursos monetarios del público. En la expresión valor se incluye : acciones, bonos, papeles comerciales, certificados de depósito de mercancías, cualquier título o derecho resultante de un proceso de titularización, cualquier título representativo de capital de riesgo, los certificados de depósito a término, las aceptaciones bancarias, las cédulas hipotecarias, y cualquier título de deuda pública $^{16}$.

- Sujeto pasivo de la conducta. El sujeto pasivo de la conducta es el inversionista que sufre detrimento patrimonial por el uso indebido de la información que no ha sido objeto de publicidad. En los mercados de valores la información incide en los precios de los títulos de renta fija o variable que son objeto de negociación.

La protección ofrecida desde el Derecho Penal, en particular con este tipo penal, contribuye a la eficiencia del mercado en la medida en que ofrece a los inversionistas la prerrogativa de tomar decisiones con la información disponible en el mercado, a la que puede acceder todo inversionista.

Eugene Fama, profesor de finanzas de la Escuela de Negocios de la Universidad de Chicago, ha planteado y defendido la hipótesis de los mercados eficientes, a partir de la afirmación de que los precios de las acciones reflejan la mejor y más completa información disponible. En esa medida, la eficiencia se obtiene cuando el mercado refleja toda la información disponible relevante para la fijación y modificación del valor de las acciones, esto es, información sobre la actividad económica, características del mercado, la actividad desarrollada por la empresa, el desempeño corporativo. El estudio hecho por FAMA, plantea tres formas de eficiencia de los precios, que varían según la información relevante que debe ser tomada para la fijación del precio del valor: eficiencia débil, intermedia y fuerte. En la primera, toda la información pasada - los precios anteriores y la historia del valor, está recogida en el precio del activo; en la segunda se refleja toda la información pasada y además la información pública existente, y en la tercera se dispone de toda la información, ya

16 El alcance de la expresión valor ha sido construido por el autor de este artículo, conforme a la descripción que aparece en el artículo 2 de la Ley 964 de 2005. 
sea pública o privada conocida solo por directores o administradores de la empresa (Alexander, 2006 ).

Respecto al inversionista, la información contribuye a orientar y dar seguridad de la inversión, le permite analizar, planificar y racionalizar sus inversiones buscando lucro, rentabilidad y una debida evaluación y administración del riesgo, así como la capacidad de pago del emisor y la solvencia del mismo. En términos generales la información tiene por objeto "...facilitarle a los inversionistas potenciales adecuados elementos para que puedan tomar sus decisiones con suficiente conocimiento de causa"17.

\section{Manipulación fraudulenta de especies inscritas en el Registro Nacional de Valores e intermediarios}

La conducta tipificada bajo esta denominación gira en torno a dos comportamientos: En primer lugar, realizar transacciones con la intención de producir mayor liquidez respecto de las acciones, bonos o valores que han sido registrados en el RNVE; y en segundo lugar, se tipifica el efectuar maniobras fraudulentas con la intención de alterar la cotización de los valores objeto de negociación.

El bien tutelado aquí es el sistema financiero colombiano. El derecho penal refuerza el enfoque dado por la normativa sectorial del mercado de valores en el sentido de generar confianza en el funcionamiento del mercado que forma parte del sistema financiero, en particular, en el sistema de formación de precios. Aquí los precios, sensibles a la información disponible en el mercado, están sometidos a distintos indicadores: la ley de oferta y demanda, la solvencia del emisor, el análisis de riesgos, la calificación del valor y del emisor. Esto significa que los precios no pueden ser objeto de manipulación por parte de los operadores en el mercado. La norma penal, de manera implícita impone que los precios deben tener un sustento en el mercado, en estudios de mercados y de riesgos, y en la situación real del emisor.

\section{JUSTIFICACIÓN DE LA PROTECCIÓN AL INVERSIONISTA DESDE LA TEORÍA DE RIESGOS}

En la teoría financiera la intervención del Estado en el mercado se concibe como un instrumento para la gestión del riesgo ${ }^{18}$. Los riesgos presentes en el mercado de valores son: riesgo de crédito, riesgo de mercado, riesgo de interés, riesgo de liquidez, riesgo país, riesgo de transferencia, operativo y legal.

El riesgo de crédito es la posibilidad de sufrir una pérdida originada por el incumplimiento de las obligaciones contractuales de pago. El incumplimiento puede

17 Memorando OJ-055, febrero 15 de 1984. Superintendencia Bancaria hoy Superintendencia Financiera de Colombia.

18 Conforme al Diccionario de la lengua española riesgo es la "contingencia o proximidad de un daño". En la teoría financiera se entiende por riesgo aquella condición en la que existe una posibilidad de desviarse del resultado esperado o deseado; una situación potencial de daño que puede producirse o no. 
tener origen en distintas circunstancias: un retroceso en la solvencia de los agentes prestatarios, problemas de liquidez, pérdidas continuadas, disminución de ingresos, reducción de los niveles de patrimonio, aumento en las tasas de interés, desempleo o ausencia de voluntad de pago.

Con la expresión riesgo de mercado se describen las posibles pérdidas que pueden producirse en activos financieros originadas por movimientos adversos de los precios de mercado. En esta tipología se incluye el riesgo de interés y el riesgo de cambio. El primero puede producirse por un movimiento en los tipos de interés que se materializa en pérdidas de valor de mercado de activos financieros sensibles al tipo de interés, como los títulos de renta fija (pública y privada) y en general, todos los activos cuyo precio sea sensible a los movimientos de los tipos de interés. El riesgo de cambio se presenta cuando los activos financieros estén expresados en moneda extranjera y el resultado esperado por los agentes no se da por la variación de la tasa de cambio ${ }^{19}$.

Riesgo de liquidez se define como la posibilidad de sufrir pérdidas originadas por la dificultad, total o parcial, de realización de ventas o compras de activos, sin sufrir una modificación sensible de los precios. También se refiere a pérdidas originadas por encontrar dificultades en la financiación necesaria para mantener el volumen de inversión deseado.

Una empresa o un inversionista pueden sufrir una pérdida como consecuencia del contexto económico y político de invertir en un país. Esta tipología de riesgo se conoce como riesgo país. Incluye las medidas tomadas por el poder público, los acontecimientos políticos internos y externos, fenómenos macroeconómicos como inflación, endeudamiento externo, crisis financieras y bancarias.

El riesgo soberano lo asume el acreedor, tanto de los Estados como de las empresas garantizadas por ellos, originado por la falta de eficacia de las acciones legales contra el prestatario o último obligado al pago, por razones de soberanía.

El riesgo operativo es la probabilidad de sufrir pérdidas financieras como consecuencia de deficiencias en los sistemas de información en los controles internos por errores en el procesamiento de las operaciones $\mathrm{u}$ otros aspectos operativos o tecnológicos. Las transacciones financieras deben ser registradas, almacenadas y contabilizadas y debe hacerse un seguimiento durante su existencia hasta que son canceladas. Cualquier discrepancia entre lo que debe ser y lo que realmente es produce la materialización de riesgo operativo.

Son manifestaciones de riesgo operativo las fallas en el mercado asociadas con: la incompetencia, el fraude y la habilidad, destreza o experiencia de los sujetos que intervienen en el mercado de valores; ejecución y confirmación de órdenes, registro de una transacción, liquidación de una compraventa, complejidad del producto, modelo de valuación erróneo; fallas en sistemas tecnológicos y errores en sistemas

19 Tasa de cambio es el valor de una moneda extranjera expresada en unidades de moneda nacional. 
de telecomunicaciones; eventos políticos y aplicación de la normativa vigente en el mercado.

Finalmente, el riesgo legal se presenta por la posibilidad de que existan errores en la formulación, interpretación y aplicación de normas jurídicas y contratos de una manera distinta a la esperada por los agentes del mercado.

Los instrumentos y mecanismos de protección reseñados en los ámbitos del Derecho del Mercado de Valores - DMV, en derecho mercantil, en la normativa del consumidor financiero y el derecho penal colombiano, desde el punto de vista de los riesgos presentes en el mercado de valores, permiten al inversionista que haga una matriz de riesgos asociados con su inversión, identificar riesgos y administrarlos. Esto significa que el Estado colombiano no asume un compromiso de extinguir riesgos con la intervención regulatoria en ninguno de los contextos explicados en el presente estudio.

\section{CONCLUSIONES}

- En el ámbito internacional, normativo y teórico, existe una tendencia a la protección jurídica del inversionista en valores que hace uso de diferentes instrumentos legales que varían según el país en el cual se implementen.

- La protección jurídica del inversionista en Colombia se halla dispersa en distintas áreas del derecho, a saber: Derecho del Mercado de Valores - DMV, derecho mercantil, normativa del consumidor financiero y derecho penal y constituyen un sistema legal de protección al inversionista.

- Cada área jurídica contiene instrumentos, mecanismos, procedimientos y organismos claramente diferenciables. La variedad de figuras se justifica por las relaciones que regula cada área y la finalidad perseguida por el regulador en cada una de ellas.

- El Estado colombiano regula la información y a partir de ella deriva la protección al inversionista: El DMV o normas sectoriales del mercado la incluye como un deber; en el derecho mercantil como un derecho del socio que se concreta en la inspección sobre libros y papeles de la compañía con información contable basada en normas internacionales de información financiera; en las normas del consumidor como un derecho; y en las normas de derecho penal como objeto de protección.

- El estudio realizado permitió demostrar que la protección al inversionista se justifica por razones de interés público, porque el inversionista es parte débil de una relación mercantil; porque opera en un mercado donde hay riesgos que el Estado colombiano no se compromete a eliminar o extinguir.

- Las razones que justifican la intervención determinan el diseño de los instrumentos legales que ofrezcan garantía, protección o tutela de los intereses del inversionista. 


\section{REFERENCIAS}

Alexander, G. (2006 ). Fundamentos de inversiones. México: Prentice Hall.

Belando, B. (2004). La protección pública del inversor en el mercado de valores. Madrid: Thompson Aranzadi.

Blanco, C. (2012, enero-junio). La información como instrumento de protección a los consumidores, los consumidores financieros y los inversionistas consumidores. Opinión Jurídica, 11(21), 135-152.

Corredor, J. (2015, septiembre-diciembre). La armonización en materia de protección al consumidor financiero en América Latina. Boletin Mexicano de Derecho Comparado, 48, 144-165.

Carmichael, J., \& Pomerleano, M. (2005). Desarrollo y regulación de instituciones financieras no bancarias. Bogotá: Banco Mundial y Mayol Ediciones.

Fontecilla, J. (2006). Algunas consideraciones sobre el interés público en la política y el derecho. Revista Española de Control Externo, (8), 135-161.

García, M. N. (2002, marzo). La importancia de la información pública societaria. Revista Iberoamericana de Mercados de Valores, (5), 3-32.

Laporta, F. (2007). El imperio de la ley. Madrid: Trota.

López, L. F., \& David, L. (2004). Estrategias de regulación financiera. Bogotá, Colombia: Universidad Externado de Colombia.

Pérez, A. (2005). La protección de los inversores y la transparencia. En J. M. Echeverría. El espacio financiero único en la Unión Europea (p. 768). Madrid: Marcial Pons.

Pyndick, R. (2003). Microeconomía. Madrid: Prentice Hall.

Quiñónez, C. (2011). El Derecho colombiano frente al uso de información privilegiada. Dixi, (13), 166-182.

Rivero, C. (2003). La protección al inversor en el mercado de valores en el Perú. Revista del Instituto Iberoamericano del Mercado de Valores, 10, 40-46.

Ruiz, R. (2002). El inversor como víctima de publicidad financiera. En L. Fernández, \& J. Ibañez. Ética y Mercado de Valores (pp. 95 a 117). Madrid: Marcial Pons.

Stiglitz, J. (2003). Los felices 90. Madrid: Roses S.A.

Valenzuela, F. (1993). La información en la sociedad anónima y el mercado de valores. Madrid: Civitas. 


\section{Normativa colombiana}

Constitución Política de Colombia

Decreto Ley 410 de 1971

Decreto 2555 de 2010

Ley 45 de 1990

Ley 599 de 2000

Ley 963 de 2005

Ley 964 de 2005

Ley 1314 de 2009

Ley 1328 de 2009

Ley 1607 de 2012

Memorando OJ-055, febrero 15 de 1984. Superintendencia Bancaria.

\section{Normativa internacional}

Decreto Supremo 93 de 2002. Normas sobre mercado de valores Perú

Ley del Mercado de Valores mexicana

Ley 6385 de 1976 y Ley 10303 de 2001 . Leyes del mercado de valores Brasil

Ley 18045 de 1981. Ley del Mercado de Valores Chile

Ley 47 de 2007 modificado por Ley 24 de 1988. Ley del Mercado de Valores español.

\section{Jurisprudencia colombiana}

Corte Constitucional. Sentencia SU-166 de 1999. M.P. Alejandro Martínez Caballero.

Corte Constitucional. Sentencia C- 406 de 2004. M.P. Clara Inés Vargas Hernández.

Corte Constitucional. Sentencia C-860 de 2006. M.P. Humberto Sierra Porto.

Corte Constitucional. Sentencia C-313 de 2013. M.P. Gabriel Eduardo Mendoza Martelo.

Corte Constitucional. Sentencia C-197 de 2012. M.P. Jorge Pretelt Chaljub. Corte Constitucional. Sentencia C-909 de 2012. M.P. Nilson Pinilla Pinilla.

Corte Constitucional. Sentencia T177 de 2013. M.P. Nilson Pinilla Pinilla. 